\title{
Grafted skeletal myoblast sheets attenuate myocardial remodeling in pacing-induced canine heart failure model
}

\author{
Hiroki Hata, $\mathrm{MD}^{\text {a }}$ Goro Matsumiya, MD, $\mathrm{PhD},{ }^{\text {a }}$ Shigeru Miyagawa, $\mathrm{MD}, \mathrm{PhD},{ }^{a}$ Haruhiko Kondoh, $\mathrm{MD}, \mathrm{PhD},{ }^{a}$ \\ Naomasa Kawaguchi, MD, PhD, ${ }^{\mathrm{b}}$ Nariaki Matsuura, MD, PhD, ${ }^{\mathrm{b}}$ Tatsuya Shimizu, MD, PhD, ${ }^{\mathrm{c}}$ Teruo Okano, PhD, \\ Hikaru Matsuda, MD, PhD, and Yoshiki Sawa, MD, PhD ${ }^{a}$
}

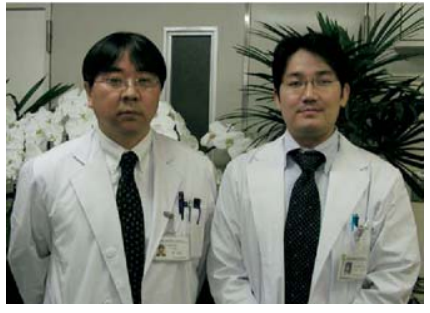

Prof Sawa and Dr Hata (left to right)
From the Division of Cardiovascular Surgery, Department of Surgery, ${ }^{\text {a }}$ Department of Molecular Pathology, School of Allied Health Science, ${ }^{\text {b }}$ Osaka University Graduate School of Medicine, Osaka, Japan; and Institute of Advanced Biomedical Engineering and Science, Tokyo Women's Medical University, ${ }^{\mathrm{c}}$ Tokyo, Japan.

Received for publication Oct 23, 2005; revisions received Dec 19, 2005; accepted for publication Jan 10, 2006.

Address for reprints: Yoshiki Sawa, MD, $\mathrm{PhD}$, Division of Cardiovascular Surgery, Department of Surgery, Osaka University Graduate School of Medicine (E1), 2-2 Yamadaoka, Suita, Osaka 565-0871, Japan (E-mail: sawa@surg1.med.osaka-u.ac.jp).

J Thorac Cardiovasc Surg 2006;132:918-24 $0022-5223 / \$ 32.00$

Copyright $\odot 2006$ by The American Association for Thoracic Surgery

doi:10.1016/j.jtcvs.2006.01.024
Objective: To overcome problems related to the intramyocardial injection of cells, including cell loss and a limited graft area, we developed a cell delivery system that uses tissue-engineered myoblast grafts grown as sheets. Here, we assessed the feasibility and efficacy of our method in a canine dilated cardiomyopathy model.

Methods: Skeletal myoblasts were incubated on temperature-responsive culture dishes, and the sheets of cells were detached by decreasing the temperature. Twelve dogs were given continuous ventricular pacing at 230 beats/min for 4 weeks; then the myoblast sheets $(n=5)$ were grafted onto the left ventricular wall or a sham operation was performed $(n=7)$. The number of cells was adjusted to $1.5 \sim 2.5 \times 10^{6}$ cells per graft, and each dog received approximately 20 grafts.

Results: The cell sheets were easily grafted onto a large area of the left ventricular surface, and there were no serious sequelae. Four weeks after graft implantation, echocardiography demonstrated that the left ventricular ejection fraction (graft, $26.0 \% \pm 5.6 \%$; control, $19.5 \% \pm 6.8 \% ; P<.05$ ) and fractional shortening (graft, $17.9 \% \pm 3.6 \%$; control, $7.8 \% \pm 2.1 \% ; P<.05$ ) were significantly ameliorated with reduced left ventricular dilatation (graft, $7.3 \pm 1.3 \mathrm{~cm}^{2}$; control, $10.2 \pm 0.4 \mathrm{~cm}^{2}$; $P<.05$ ) and increased wall thickness (graft, $5.6 \pm 0.7 \mathrm{~mm}$; control, $4.4 \pm 0.6 \mathrm{~mm}$; $P<.05)$. Histologic evidence indicated the grafted myoblasts had survived, accompanied by a significant reduction in fibrosis and apoptosis, and a significant increase in proliferation.

Conclusions: Grafting of skeletal myoblast sheets attenuated cardiac remodeling and improved cardiac performance. This novel method was feasible and effective in a large animal model, suggesting an innovative and promising strategy for treating patients with end-stage dilated cardiomyopathy.

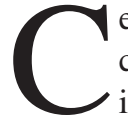
ell transplantation (Tx) into impaired myocardium, also known as cellular cardiomyoplasty, has been widely investigated, ${ }^{1,2}$ and various type of cells, including fetal cardiomyocytes, ${ }^{3}$ embryonic stem cells, ${ }^{4}$ fibroblasts, ${ }^{5}$ smooth muscle cells, ${ }^{6}$ endothelial cells,${ }^{7}$ bone marrow stem cells,${ }^{8}$ and skeletal myoblasts, ${ }^{9}$ have been used for the therapy. Among them, autologous bone marrow stem cells and skeletal myoblasts are considered the most likely to be successful and have been used clinically to treat ischemic cardiomyopathy. ${ }^{10-12}$ In these clinical cases, the usual method of cell Tx into the myocardium is direct intramyocardial injection with a fine needle. However, this needle injection method has some disadvantages, including cell loss caused by leakage of injected cells from the myocardium, ${ }^{12}$ poor survival of the grafted cells, myocardial damage after mechanical injury by the needle, and subsequent acute inflammation.,13 


$$
\begin{array}{ll}
\text { Abbreviations and Acronyms } \\
\begin{array}{ll}
\text { CK } & =\text { color kinesis } \\
\text { DCM } & =\text { dilated cardiomyopathy } \\
\text { FS } & =\text { fractional shortening } \\
\text { LV } & =\text { left ventricular } \\
\text { LVAWTh } & =\text { left ventricular anterior wall thickness } \\
\text { LVEF } & =\text { left ventricular ejection fraction } \\
\text { LVESA } & =\text { end-systolic LV area } \\
\text { PCNA } & =\text { proliferating cell nuclear antigen } \\
\text { TUNEL } & =\text { terminal deoxynucleotidyl transferase- } \\
& \text { mediated dUTP nick end labeling }
\end{array}
\end{array}
$$

Another problem accompanying the injection method is difficulty in transplanting cells over a large area. Clinical treatment for diffusely impaired myocardium, such as that seen in dilated cardiomyopathy (DCM), may require a technique with fewer disadvantages.

To resolve these difficulties, we recently developed a novel cell delivery system that uses a tissue-engineered sheet of autologous skeletal myoblasts for grafting; the sheet is fabricated on temperature-responsive culture surfaces coated with a temperature-responsive polymer, $\operatorname{poly}(N$ iso-propylacrylamide). Simply by reducing the temperature, and without enzymatic digestion, confluent cells on these surfaces can be harvested as a single, unsupported, contiguous sheet. Intercellular junctions form in the sheets, and extracellular matrix is retained on the basal surface: Both are thought to play an important role in cell survival and graft adhesion. ${ }^{14-17}$

With this technique, we have already obtained several satisfactory results in treating myocardial infarction in some animal models. ${ }^{14,15}$ We next hypothesized that this innovative graft could be applicable to the treatment of DCM. Therefore, we designed a preclinical study to test the feasibility and usefulness of using these myoblast sheets as grafts to treat end-stage DCM in large mammals.

\section{Materials and Methods \\ Rapid Pacing-induced Canine Heart Failure Model}

Twelve adult female beagles weighing 8 to $10 \mathrm{~kg}$ were used in this experiment. All animals received humane care in compliance with the "Principles of Laboratory Animal Care" formulated by the National Society for Medical Research and the "Guide for the Care and Use of Laboratory Animals" prepared by the Institute of Laboratory Animal Resource and published by the National Institutes of Health (NIH publication No. 85-23, 1996).

The dogs were anesthetized with intravenous administration of ketamine $(6 \mathrm{mg} / \mathrm{kg})$ and sodium pentobarbital $(6 \mathrm{mg} / \mathrm{kg})$, intubated endotracheally, and given mechanical ventilation. Anesthesia was maintained with inhaled sevoflurane $(1.0 \% \sim 2.0 \%)$. Under sterile conditions, a bipolar pacing lead (Star Medical BT-45P; Star Medical, Tokyo, Japan) was surgically fixed to the right ventricular free wall surface and connected to a pulse generator (Star
Medical SIP-501; Star Medical) placed in a subcutaneous pocket. The muscle and skin were closed in layers, and the dogs were then taken off the anesthetics. Their heartbeats were monitored during and after the operation for a few hours to check for arrhythmia. One day after the operation, rapid ventricular pacing was started at a rate of 230 beats/min. The pacing was temporarily stopped during the assessment of cardiac function and during surgery. The rate control of the implanted pulse generator was manipulated beyond the cutis using a magnet with the animal awake.

\section{Preparation of Skeletal Myoblast Sheets for Grafting}

With the dog under general anesthesia, skeletal muscle weighing approximately $2 \mathrm{~g}$ was removed from the pretibial region. After the addition of trypsin-EDTA (Gibco, Grand Island, NY), excessive connective tissue was carefully removed using $26 \mathrm{G}$ needles to minimize the content of contaminating fibroblasts, and the muscle tissue was minced until the fine pieces formed a homogeneous mass. The specimens were then incubated at $37^{\circ}$ in a shaker bath with $0.5 \%$ type I collagenase (Gibco) in Dulbecco's modified Eagle's medium (Gibco). After brief placement, the fluid was collected, and the same volume of culture medium, SkBM (Cambrex, Walkersville, Md) supplemented with fetal bovine serum (Thermo Trace, Melbourne, Australia), was added to halt the enzymatic digestion process. The cells were collected by centrifugation, and the putative myoblasts were seeded into five $150-\mathrm{cm}^{2}$ polystyrene flasks after removal of fibroblasts by sedimentation for a few hours and cultured in SkBM at $37^{\circ}$. During the culture process, we maintained cell densities at less than $70 \%$ confluence by carrying out passaging of cells for 1 time to prevent skeletal myoblasts from premature differentiation and fusion process resulting in myotubes formation. When the cells became approximately $70 \%$ confluent after 10 to 11 days cultivation (Figure 1,A), the cells were dissociated from the flasks with trypsin-EDTA and reincubated on 60-mm temperature-responsive culture dishes (Cellseed, Tokyo, Japan) at $37^{\circ}$ with the cell numbers adjusted to $1.5 \sim 2.5 \times 10^{6}$ per dish. More than $90 \%$ of these cells were desmin positive (data not shown). After 24 hours, the dishes were moved to a refrigerator set at $20^{\circ}$ and left there for 30 minutes. During that time the myoblast sheets detached spontaneously from the surfaces (Figure 1, B). Almost all of the seeded myoblasts were organized into the graft, and there was hardly any loss of cells. Each sheet had a diameter of 30 to $40 \mathrm{~mm}$ and consisted of layers of skeletal myoblasts; the sheets were approximately $90-\mu \mathrm{m}$ thick (Figure $1, C$ ). Approximately 20 sheets were obtained from the original $2 \mathrm{~g}$ of skeletal muscle.

\section{Grafting the Myoblast Sheets}

After 28 days of rapid ventricular pacing, the autologous skeletal myoblast sheets were grafted onto the left ventricle (Tx group, $\mathrm{n}=$ $5)$ or a sham operation was performed $(C$ group, $n=7)$. The surgical approach was through a left-sided thoracotomy under general anesthesia with the pacemaker off. In the Tx group, 18 to 21 sheet grafts were implanted onto the surface of the anterior and lateral left ventricular (LV) wall so that each dog received $4.0 \times$ $10^{7}$ cells in total. Basically, we tried to implant as many sheets as possible onto the visible heart surface from the operative field. Because piling up 4 or more sheets caused the central necrosis of the myoblasts, presumably as a result of the lack in oxygen supply, 

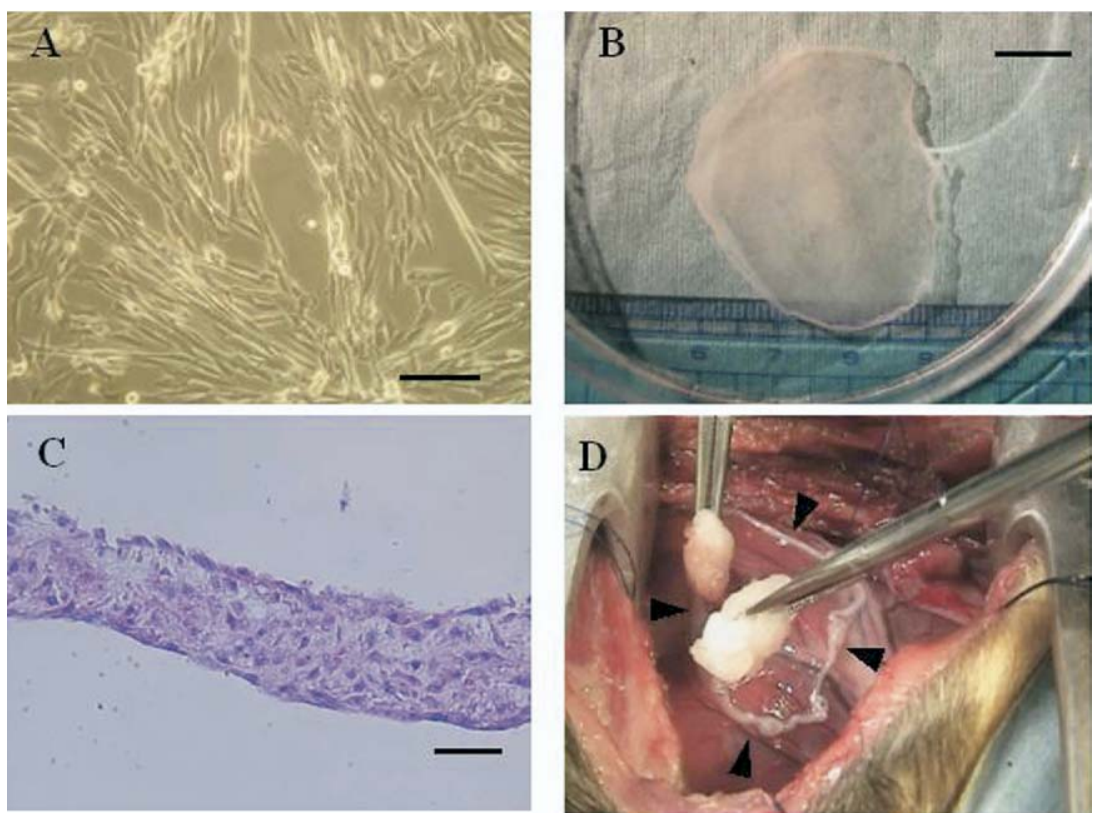

Figure 1. Manufacture and grafting of skeletal myoblast sheets. A, Primary cultures of autologous skeletal myoblasts showing a spindle-shaped appearance. B, Each graft was soft and limp, with a diameter of $\mathbf{3 0}$ to $\mathbf{4 0}$ $\mathrm{mm}$. C, Cross-section of a graft, which was approximately $90-\mu \mathrm{m}$ thick. D, Graft (arrows) was placed and smoothed out on the LV wall. Scale bar: $50 \mu \mathrm{m}(A, C)$ and $10 \mathrm{~mm}(B)$. we decided to pile 3 layers of the myoblast sheet over the broad surface of the impaired heart. When the grafts were applied, they were smoothed out on the LV wall, where surface tension kept them stuck tightly to the epicardium in most cases (Figure 1, D). If necessary, the implanted grafts were fixed at several points with 6-0 polypropylene epicardial sutures. In the $\mathrm{C}$ group, a left-sided thoracotomy and incisions in the pericardium were performed. The rapid pacing was restarted the day after surgery and was maintained at the same rate as before.

\section{Measurement of Canine Cardiac Function}

At the prepacing state, baseline (just before the graft implantation or sham operation), and every 2 weeks after the surgical treatment, each dog was given general anesthesia and cardiac ultrasonography was performed using a SONOS 5500 (Hewlett-Packard, Palo Alto, Calif). The end-systolic and end-diastolic LV areas were measured at the level of the papillary muscles and mitral valve (LVESApm, LVESAmv, LVEDApm, LVEDAmv). The end-systolic and end-diastolic LV dimensions along the long-axis (LVLs, LVLd) were also measured. In addition, we determined the endsystolic and end-diastolic LV dimension (LVDs, LVDd), and LV anterior wall thickness (LVAWTh) in short-axis views in the M-mode. All data are presented as the average of measurements of 3 selected beats. Simpson's formula was used to calculate the end-systolic and end-diastolic LV volume (LVVs, LVVd). The LV ejection fraction (LVEF) and LV percentage of fractional shortening (FS) were calculated as follows, respectively:

(1) $\operatorname{LVVs}(d)=\operatorname{LVLs}(d) / 3 \times\{\operatorname{LVES}(\mathrm{D}) \mathrm{Amv}+$ $[\operatorname{LVES}(\mathrm{D}) \mathrm{Amv}+\operatorname{LVES}(\mathrm{D}) \mathrm{Apm}] / 2+\operatorname{LVES}(\mathrm{D}) \mathrm{Apm} / 3\}$

(2) $\operatorname{LVEF}(\%)=[(\mathrm{LVVd}-\mathrm{LVVs}) / \mathrm{LVVd}] \times 100$

(3) $\mathrm{LV} \% \mathrm{FS}=[(\mathrm{LVDd}-$ LVDs $) / \mathrm{LVDd}] \times 100$

Echocardiographic Evaluation With Color Kinesis

For the further assessment of LV regional function, we applied color kinesis (CK) analysis using the SONOS 5500. Regional wall motion was assessed by computing the pixel counts in each LV segment; the segment boundaries were automatically determined by custom-designed software. Regional systolic function was appraised using the regional fractional area changes, which express the percentage of the end-systolic area of the regional LV wall motion. ${ }^{18}$ Regional diastolic function was evaluated using the CK-diastolic index in each region, which was defined as the LV segmental filling fraction during the first one-third of the diastolic filling time, and expressed as a percentage. ${ }^{19}$

\section{Histologic Assessment}

Four weeks after the surgical treatment, the dogs were given an injection of heparin and then euthanized. The hearts were removed, and at least 4 myocardial samples were excised from various regions of the same heart. They were then fixed with $10 \%$ buffered formalin and paraffin-embedded or frozen in liquid nitrogen. The fixed specimens were sectioned to a 5- $\mu \mathrm{m}$ thickness. Hematoxylin-eosin staining and Masson's trichrome staining were performed for the morphometry analysis. To test for the existence of skeletal muscle cells, sections were incubated with mouse monoclonal anti-Nebulin (Sigma-Aldrich, St Louis, Mo), which is specific for skeletal muscle. To assess the extent of fibrosis, picrosirius red staining was used, and the proportion of the fibrosisoccupying area (percent fibrosis) was calculated. To label vascular endothelial cells, immunohistochemical staining for factor VIIIrelated antigen (Dako EPOS Anti-human Von Willebrand Factor/ HRP; DakoCytomation, Glostrup, Denmark) was performed. Periodic acid-Schiff staining was used to label myocytes so their diameters could be measured. To define proliferative activity, we used mouse monoclonal antiproliferating cell nuclear antigen (PCNA) (Sigma-Aldrich). To determine the extent of apoptosis, sections from frozen tissue samples were subjected to terminal deoxynucleotidyl transferase-mediated dUTP nick end labeling (TUNEL) with an in situ apoptosis detection kit (Apoptag; Chemicon, Temecula, Calif). Computed appraisal of pathology (percent 
A

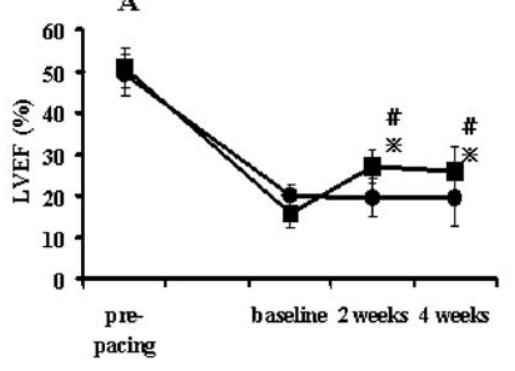

C

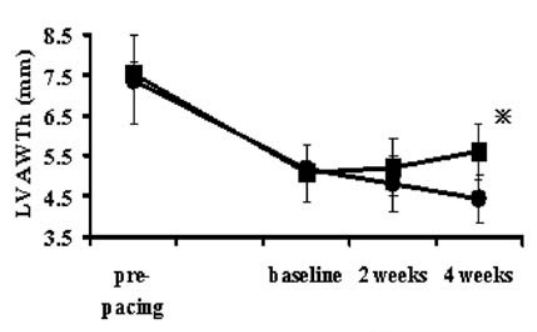

$\rightarrow-c-T x$
B

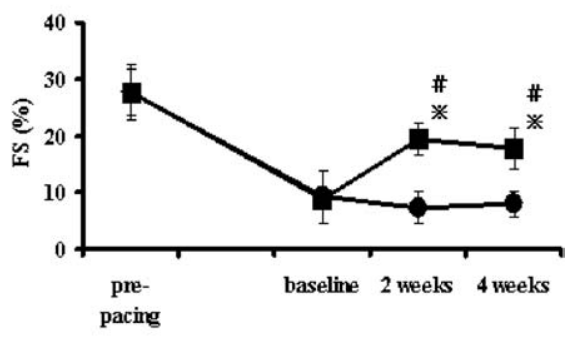

D

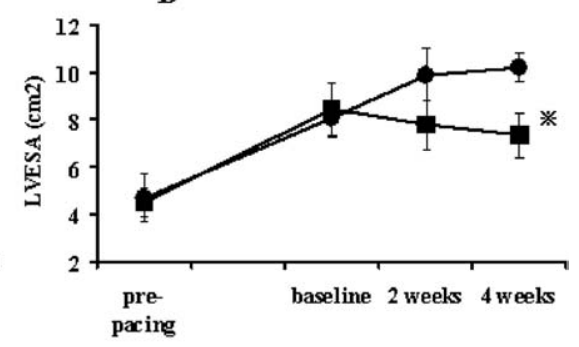

Figure 2. Echocardiographic findings. LVEF (A), LV\%FS (B), and LVAWTh (C) increased, whereas LVESA (D) decreased after implantation in the Tx group. Data are expressed as the means \pm standard error of mean. ${ }^{*} P<$ .05 versus the $C$ group. \#P $<.05$ versus the baseline. fibrosis, vascular density, myocyte diameter, and percentage of TUNEL-positive nuclei) was performed on 10 randomly chosen optical fields $\left(0.56 \mathrm{~mm}^{2}\right)$ for each sample.

\section{Statistical Analysis}

All values are expressed as the means \pm standard error of mean. Statistical comparisons of the cardiac function data were performed using repeated-measures analysis of variance followed by a Bonferroni test for individual significant differences. Histologic data were compared using the Student $t$ test.

\section{Results}

\section{Canine Dilated Cardiomyopathy Model}

After rapid ventricular pacing for 4 weeks, all of the dogs developed marked LV dysfunction with a dilated chamber (Figure 2). Neither critical arrhythmia nor any other complication associated with graft implantation was identified in any of the dogs after the surgical procedure.

\section{Implantation of Myoblast Grafts Improved Cardiac Function}

The echocardiography showed significant improvement of LVEF and LV percentage of FS in the Tx group between pre-Tx and 4 weeks post-Tx. It also showed significant improvement of these systolic functions in the Tx group compared with the $\mathrm{C}$ group at 2 and 4 weeks after graft implantation (Figure 2, $A, B$ ). These functional improvements were observed as soon as 1 week post-Tx (data not shown). The Tx group showed a significant increase in LVAWTh and a significant decrease in LVESA compared with the $\mathrm{C}$ group (Figure 2, C,D). In regard to the $\mathrm{LV}$ chamber volume, LVVs of the Tx group were significantly smaller than that of the C group (Tx, $426.4 \pm 87.1 \mathrm{~mL}$; C, $618.6 \pm 82.4 \mathrm{~mL} ; P<.05) 4$ weeks after graft implantation, whereas there was no significant difference between the 2 groups at baseline (Tx, $458.1 \pm 102.0 \mathrm{~mL}$; C, $441.4 \pm 94.4$ $\mathrm{mL})$. LVVd of the Tx group tended to be smaller than that of the $\mathrm{C}$ group 4 weeks after treatment, although the difference was not statistically significant $(\mathrm{Tx}, 584.3 \pm 157.7$ $\mathrm{mL} ; \mathrm{C}, 774.6 \pm 144.5 \mathrm{~mL} ; P=.10)$.

In the assessment of regional fractional area changes in the anterolateral segment, where the myoblast grafts were implanted, no significant difference was seen at baseline between the 2 groups by $\mathrm{CK}$ analysis (Tx, 30.4\% $\pm 5.4 \%$; C, $29.2 \% \pm 4.2 \%$ ). Four weeks after the operation, the regional fractional area changes had increased significantly in the Tx group, whereas it decreased in the $\mathrm{C}$ group (Tx, $40.0 \% \pm 4.0 \% ; \mathrm{C}, 25.0 \% \pm 4.5 \% ; P<$ $.01)$. In the assessment of regional LV diastolic function, the CK-diastolic indices in the anterolateral segment were significantly different between the 2 groups 4 weeks after the operation $(\mathrm{Tx}, 50.0 \% \pm 12.0 \%$; C, $34.0 \% \pm$ $7.9 \% ; P<.05)$, although there was no significant difference between the groups at baseline (Tx, 36.4\% $\pm 8.0 \%$; $\mathrm{C}, 35.7 \% \pm 7.2 \%$ ). This high value of the CK-diastolic indices in the Tx group means that the LV wall could expand satisfactorily in the early diastolic phase. These echocardiographic assessments using CK indicated a clear improvement of the cardiac performance in the systolic and diastolic function in the Tx group. 

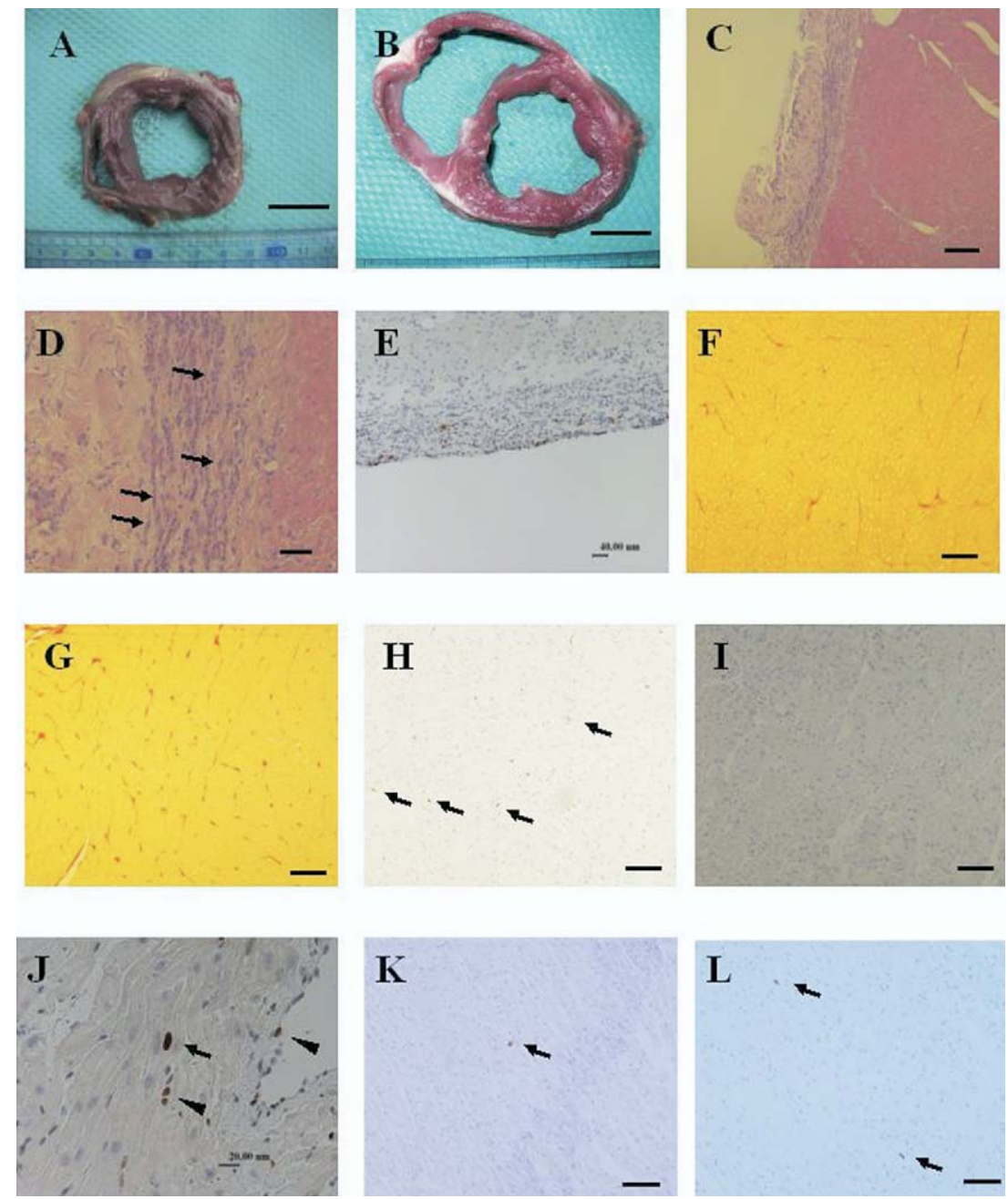

Figure 3. Postsurgical histologic findings. Macroscopic findings of cross-sectional specimens of canine heart. Tx group (A) showed an increased LV wall thickness and decreased LV thickness, compared with C group (B). Photomicrograph of a section through the ventricular wall that was stained with hematoxylineosin and contained grafted cells that survived and formed layers over the epicardium (C). Higher magnification showing elongated skeletal myoblasts (arrows) with infiltrated, round inflammatory cells (D). Survival of the grafted myoblasts was confirmed in adjacent sections by staining with skeletal muscle-specific nebulin (E). Picrosirius red staining showed a significant reduction of fibrosis in Tx group (F) compared with C group (G). PCNA-positive cells were found in some areas of the myocardium in Tx group (arrows) (H), but none were identified in the $\mathrm{C}$ group (I). Higher magnification of PCNA-positive cells including cardiomyocyte with striated pattern (arrows) and interstitial cells (arrowhead) (J). The number of TUNEL-positive myocytes (arrows) was significantly lower in Tx group (K) than in $C$ group (L). Scale bar: $20 \mathrm{~mm}(A, B)$; $100 \mu \mathrm{m}$ (C, F-I, K, L); $40 \mu \mathrm{m}$ (D, E); and $20 \mu \mathrm{m}$ (J).

\section{Graft Survival and Attenuation of Cardiac}

\section{Remodeling After Graft Implantation}

Macroscopic examinations confirmed that LV dilatation was generally inhibited and that the LV wall thickness was maintained in the Tx group compared with the $\mathrm{C}$ group (Figure 3, A,B). In the Tx group, no tumor formation of grafted cells was observed. There was a thin layer of whitish tissue on the surfaces of the anterior and lateral LV walls, which coincided with the sites of implantation of the grafts. Microscopic examination of the whitish tissue revealed elongated skeletal muscle cells in some layers over the epicardium (Figure 3, $C, D$ ); these were confirmed to be of skeletal origin by staining for skeletal muscle-specific nebulin (Figure 3,E). In the same region of the grafted cell layer, moderate angiogenesis and infiltration of inflammatory cells were also observed.

In the native myocardial tissue, picrosirius red staining showed an obvious reduction of fibrosis in the Tx group compared with the $\mathrm{C}$ group (Figure 3,F,G), and fibrosis was also significantly reduced $(\mathrm{Tx}, 0.3 \% \pm 0.1 \% ; \mathrm{C}, 2.6 \% \pm$
$0.6 \% ; P<.05)$. Vascular density in the Tx group was higher than in the $\mathrm{C}$ group, although the difference was not significant (Tx, $15.8 \% \pm 5.4 \%$; C, $12.9 \% \pm 3.6 \%$ ). PCNA-positive cells were identified only in the Tx group $\left(23.7 \pm 3.8 / \mathrm{mm}^{2}\right)$ (Figure $3, H, I)$, and some of them appeared to be myocardial cells, with a striated pattern and long thin nuclei; the remainder appeared to be interstitial cells (Figure 3,J). The percentage of TUNELpositive myocytes was significantly lower in the Tx group than in the $\mathrm{C}$ group (Tx, $0.16 \% \pm 0.10 \% ; \mathrm{C}, 0.45 \% \pm$ $0.16 \% ; P<.05$ ) (Figure 3, K,L). The mean diameter of the myocytes in the Tx group was smaller than in the $\mathrm{C}$ group, although the difference was not significant (Tx, $13.1 \pm 1.4$ $\mu \mathrm{m} ; \mathrm{C}, 16.3 \pm 2.9 \mu \mathrm{m})$. These histologic findings were universally identified in the native myocardial tissue without distinction of distance from the grafted region.

\section{Discussion}

In the present preclinical study, we demonstrated that grafted autologous skeletal myoblast sheets attenuated car- 
diac remodeling and improved LV systolic and diastolic function in a canine model of DCM. This study differs from other reported cardiomyoplasty methods in that the application of these grafts allowed us to address diffuse lesions and reduce cell loss. To the best of our knowledge, this is the first report in which grafts of tissue-engineered myoblast sheets were successfully used to improve cardiac performance in a large animal model of DCM.

Over the past decade, regenerative therapies based on cell Tx have been explored as potential novel approaches for the treatment of end-stage heart failure. Among the many candidate cells, skeletal myoblasts have been considered to have several advantages, including autologous origin, ease of procurement, high proliferative potential in vitro, and strong resistance to hypoxia followed by ischemia. ${ }^{2,4}$ Thus, they are one of the cell sources that is most strongly expected to be successful for cell Tx therapy in clinical applications.

Although accumulated experimental and clinical results have demonstrated the feasibility and efficacy of transplanting skeletal myoblasts to treat ischemic cardiomyopathy, ${ }^{11,12}$ limited preclinical data are available on the treatment of DCM. ${ }^{20}$ In the present study, we used the dog rapid-pacing heart failure model, which is known to simulate human DCM, not only in terms of cellular and molecular changes but also in terms of the resulting functional and structural characteristics. ${ }^{21,22}$ In this model, as in human idiopathic DCM, cell death by apoptosis may play a significant role in cardiac failure. ${ }^{23-25}$ The loss of myocytes leads to interstitial fibrosis and edema, hypertrophy of the surviving myocytes, and chamber dilation. As a consequence of this myocardial remodeling, cardiac function both deteriorates and decompensates. Thus, it was very important to investigate these pathologic changes in considering the clinical application of our therapy.

We are still uncertain how such thin sheets of myoblasts and the relatively small volume of grafted cells that survived outside the epicardium could inhibit cardiac remodeling and induce improvement in cardiac function. The number of surviving myoblasts may be too small for these cells to make such a dramatic contribution by themselves. One of the most likely mechanisms we have speculated about is a paracrine effect of growth factors secreted from the skeletal myoblasts, such as hepatocyte growth factor. Our pathologic findings, including the antifibrotic and antiapoptotic effects, angiogenesis, and proliferation of myocytes, were consistent with the reported effects of hepatocyte growth factor and vascular endothelial growth factor. ${ }^{26,27}$ In fact, Tatsumi and colleagues ${ }^{28}$ reported that hepatocyte growth factor is present in adult skeletal muscle. Moreover, our recent research also revealed that not only hepatocyte growth factor but also other growth factors, including stromalcell derived factor-1 and vascular endothelial growth factor, are highly expressed by the skeletal myoblast sheets in vitro and in vivo. ${ }^{14}$ Thus, although we have not assessed the expression of these growth factors here, we think there is a good possibility that they play an important role in cardiomyoplasty. Several PCNA-positive cells with striated pattern were identified in the implantation group, but none were observed in the control group. This may suggest another possible mechanism that the immigrated and proliferating cells in the myocardium have active and passive effects that may increase ventricular contractility and decrease LV wall stress. ${ }^{12,13}$ If these speculative mechanisms are operative in vivo, it may not be necessary for the grafted cells to infiltrate into the native myocardium to exert their effects.

Beneficial for cell Tx therapy, the myoblast sheets had a preserved extracellular matrix and intracellular junctions, which may be essential to the primary attachment and survival of the grafted cells. ${ }^{14-17}$

Several important aspects of this method remain to be researched. The first is that a longer-term assessment of the outcome is needed. Second, the optimum number of myoblasts and/or layers of sheets needs to be determined. Although we obtained favorable results by applying 3 layers of grafts in the present study, it is unclear whether still greater improvement would be achieved by increasing the number of graft layers or fewer graft numbers could affect the same amount of improvement. Third, the optimal timing for the implantation of myoblast grafts with respect to the stage of the disease also needs to be investigated. In the canine heart failure model used here, heart function recovers quickly after the cessation of rapid ventricular pacing. ${ }^{22}$ Therefore, it remains uncertain when a decompensated and irreversible state of heart failure has been attained and whether such complete failure can be reversed by this therapy. Additional studies are required to determine the optimum timing of this treatment for clinical trials.

\section{Conclusions}

We found that the present novel cell delivery system using sheets of autologous skeletal myoblasts as grafts was satisfactorily feasible and effective for treating global heart failure. Because pathologic similarities exist between this canine experimental model and human DCM, the present method is a promising regeneration therapy that may provide great benefit to patients with chronic heart failure caused by DCM.

We thank Dr Satoru Kitagawa-Sakakida for critical review of the article, Mrs Masako Yokoyama for expert assistance with reverse transcriptase-polymerase chain reaction, and Mr Shigeru Matsumi for excellent technical support. 


\section{References}

1. Marelli D, Desrosiers C, el-Alfy M, Kao RL, Chiu RC. Cell transplantation for myocardial repair: an experimental approach. Cell Transplant. 1992;1:383-90.

2. Menasche P. Cell transplantation in myocardium. Ann Thorac Surg. 2003;75:S20-S8.

3. Reinecke H, Zhang M, Bartosek T, Murry CE. Survival, integration, and differentiation of cardiomyocyte grafts: a study in normal and injured rat hearts. Circulation. 1999;100:193-202.

4. Minami E, Reinecke H, Murry CE. Skeletal muscle meets cardiac muscle. Friends or foes? J Am Coll Cardiol. 2003;41:1084-6.

5. Hutcheson KA, Atkins BZ, Hueman MT, Hopkins MB, Glower DD, Taylor DA. Comparison of benefits on myocardial performance of cellular cardiomyoplasty with skeletal myoblasts and fibroblasts. Cell Transplant. 2000;9:359-68.

6. Sakai T, Li RK, Weisel RD, Mickle DA, Jia ZQ, Tomita S, et al. Fetal cell transplantation: a comparison of three cell types. J Thorac Cardiovasc Surg. 1999;118:715-24.

7. Kim EJ, Li RK, Weisel RD, Mickle DA, Jia ZQ, Tomita S, et al. Angiogenesis by endothelial cell transplantation. J Thorac Cardiovasc Surg. 2001;122:963-71.

8. Orlic D, Kajstura J, Chimenti S, Jakoniuk I, Anderson SM, Li B, et al. Bone marrow cells regenerate infarcted myocardium. Nature. 2001; 410:701-5.

9. Taylor DA, Atkins BZ, Hungspreugs P, Jones TR, Reedy MC, Hutcheson KA, et al. Regenerating functional myocardium: improved performance after skeletal myoblast transplantation. Nat Med. 1998; 4:929-33.

10. Strauer BE, Brehm M, Zeus T, Kostering M, Hernandez A, Sorg RV, et al. Repair of infarcted myocardium by autologous intracoronary mononuclear bone marrow cell transplantation in humans. Circulation. 2002;106:1913-8.

11. Menasche P, Hagege AA, Vilquin JT, Desnos M, Abergel E, Pouzet B, et al. Autologous skeletal myoblast transplantation for severe postinfarction left ventricular dysfunction. J Am Coll Cardiol. 2003;41: 1078-83.

12. Pagani FD, DerSimonian H, Zawadzka A, Wetzel K, Edge AS, Jacoby $\mathrm{DB}$, et al. Autologous skeletal myoblasts transplanted to ischemiadamaged myocardium in humans. Histological analysis of cell survival and differentiation. J Am Coll Cardiol. 2003;41:879-88.

13. Suzuki K, Murtuza B, Fukushima S, Smolenski RT, Varela-Carver A, Coppen SR, et al. Targeted cell delivery into infarcted rat hearts by retrograde intracoronary infusion: distribution, dynamics, and influence on cardiac function. Circulation. 2004;110(Suppl II):II-225-30.

14. Memon IA, Sawa Y, Fukushima N, Matsumiya G, Miyagawa S, Taketani S, et al. Repair of impaired myocardium by means of implantation of engineered autologous myoblasts sheets. J Thorac Cardiovasc Surg. 2005;130:1333-41.
15. Miyagawa S, Sawa Y, Kitagawa-Sakakida S, Taketani S, Kondoh H, Memon IA, et al. Tissue cardiomyoplasty using bioengineered contractile cardiomyocyte sheets to repair damaged myocardium: their integration with recipient myocardium. Transplantation. 2005;80: 1586-95.

16. Okano T, Yamada N, Okuhara M, Sakai H, Sakurai Y. Mechanism of cell detachment from temperature-modulated, hydrophilic-hydrophobic polymer surfaces. Biomaterials. 1995;16:297-303.

17. Shimizu T, Yamato M, Kikuchi A, Okano T. Cell sheet engineering for myocardial tissue reconstruction. Biomaterials. 2003;24:2309-16.

18. Rajnoch C, Chachques JC, Berrebi A, Bruneval P, Benoit MO, Carpentier A. Cellular therapy reverses myocardial dysfunction. J Thorac Cardiovasc Surg. 2001;121:871-8.

19. Ishii K, Makita T, Okuda N. Diagnosis of multivessel coronary vasospasm by detecting postischemic regional left ventricular delayed relaxation on echocardiography using color kinesis. Circ J. 2004;68: 483-7.

20. Pouly J, Hagege AA, Vilquin JT, Bissery A, Rouche A, Bruneval P, et al. Does the functional efficacy of skeletal myoblast transplantation extend to nonischemic cardiomyopathy? Circulation. 2004;110: 1626-31.

21. Armstrong PW, Stopps TP, Ford SE, de Bold AJ. Rapid ventricular pacing in the dog: pathophysiologic studies of heart failure. Circulation. 1986;74:1075-84.

22. Takagaki M, McCarthy PM, Tabata T, Dessoffy R, Cardon LA, Connor $\mathbf{J}$, et al. Induction and maintenance of an experimental model of severe cardiomyopathy with a novel protocol of rapid ventricular pacing. J Thorac Cardiovasc Surg. 2002;123:544-9.

23. Leri A, Liu Y, Malhotra A, Li Q, Stiegler P, Claudio PP, et al. Pacing-induced heart failure in dogs enhances the expression of p53 and p53-dependent genes in ventricular myocytes. Circulation. 1998; 97:194-203.

24. Heinke MY, Yao M, Chang D, Einstein R, dos Remedios CG. Apoptosis of ventricular and atrial myocytes from pacing-induced canine heart failure. Cardiovasc Res. 2001;49:127-34.

25. Olivetti G, Abbi R, Quaini F, Kajstura J, Cheng W, Nitahara JA, et al. Apoptosis in the failing human heart. N Engl J Med. 1997;336: 1131-41.

26. Miyagawa S, Sawa Y, Taketani S, Kawaguchi N, Nakamura T, Matsuura $\mathrm{N}$, et al. Myocardial regeneration therapy for heart failure: hepatocyte growth factor enhances the effect of cellular cardiomyoplasty. Circulation. 2002;105:2556-61.

27. Ahmet I, Sawa Y, Iwata K, Matsuda H. Gene transfection of hepatocyte growth factor attenuates cardiac remodeling in the canine heart: a novel gene therapy for cardiomyopathy. J Thorac Cardiovasc Surg. 2002; 124:957-63.

28. Tatsumi R, Anderson JE, Nevoret CJ, Halevy O, Allen RE. HGF/SF is present in normal adult skeletal muscle and is capable of activating satellite cells. Dev Biol. 1998;194:114-28. 